\author{
Abstracta Iranica \\ Abstracta Iranica Revue bibliographique pour le domaine irano-aryen \\ Volume 32-33 | 2013 \\ Comptes rendus des publications de 2009-2010
}

\title{
PRÉFACE - Abstracta Iranica 32-33 - 2009-2010
}

\section{Rémy Boucharlat et Poupak Rafii Nejad}

\section{(2) OpenEdition}

\section{Journals}

\section{Édition électronique}

URL : http://journals.openedition.org/abstractairanica/41087

DOI : 10.4000/abstractairanica.41087

ISSN : 1961-960X

Éditeur :

CNRS (UMR 7528 Mondes iraniens et indiens), Éditions de l'IFRI

Édition imprimée

Date de publication : 1 décembre 2013

ISSN : 0240-8910

\section{Référence électronique}

Rémy Boucharlat et Poupak Rafii Nejad, «PRÉFACE - Abstracta Iranica 32-33 - 2009-2010», Abstracta Iranica [En ligne], Volume 32-33 | 2013, mis en ligne le 01 juillet 2016, consulté le 26 septembre 2020. URL : http://journals.openedition.org/abstractairanica/41087 ; DOI : https://doi.org/ 10.4000/abstractairanica.41087

Ce document a été généré automatiquement le 26 septembre 2020.

Tous droits réservés 


\title{
PRÉFACE - Abstracta Iranica 32-33 - 2009-2010
}

\author{
Rémy Boucharlat et Poupak Rafii Nejad
}

1 Ce volume double d'Abstracta Iranica couvre les publications des cuvées 2009-2010. Il parait avec un retard considérable, pour lequel nous devons présenter nos excuses.

2 Au cours de son existence depuis trente-cinq ans, Abstracta Iranica a connu des phases de réorganisation, et a suivi l'évolution des techniques documentaires et éditoriales. La revue a su s'adapter aux changements nécessaires, mais aussi, a parfois choisi, après réflexion, des orientations, et l'adaptation aux nouveaux modes d'édition, de diffusion et de consultation.

3 A l'origine supplément à Studia Iranica, Abstracta Iranica est devenu une co-édition de l'IFRI, et l'UMR Mondes iranien et indien à Paris. Elaboré dans le cadre de celle-ci, à Paris, le travail de mise en forme (mise en page, numérotation, renvois d'une rubrique à une autre) est réalisé à l'IFRI, à Téhéran. Or le fonctionnement de l'Institut a été sérieusement perturbé ces dernières années. Se sont ajoutés des problèmes privés pour plusieurs personnes qui œuvrent à l'élaboration de la revue.

4 L'évolution des sciences humaines et sociales sur le monde contemporain est allée vers une plus grande interdisciplinarité, de sorte qu'il est devenu difficile, parfois impossible, de classer un article ou un ouvrage dans une seule discipline, telle que sociologie ou sciences politiques. C'est pourquoi, pour le monde iranien contemporain, les rubriques auparavant numérotées 12 à 16 sont désormais fusionnées à partir de ce numéro.

5 À la suite de cette parution papier, la mise en ligne sera effectuée rapidement; celle du volume 31 a été effectuée en juillet 2013. A présent, les contributeurs travaillent à rendre compte des parutions des années 2011, 2012 et 2013 auxquelles correspondra le numéro " papier » 34-36. Mais la Rédaction a décidé d'un changement important dans la version en ligne. Afin de suivre l'actualité des parutions de plus près, cette mise en ligne n'attendra plus la finalisation de la version papier, mais devancera celle-ci, intervenant plusieurs fois dans l'année. Le succès de cette version que nous pouvons vérifier par les statistiques s'en trouvera renforcé. 
6 Ainsi Abstracta Iranica continue grâce au travail bénévole de plusieurs dizaines de collaborateurs spécialistes dans une quinzaine de pays. En se renouvelant, Abstracta Iranica sera désormais plus réactif et ainsi répondra plus rapidement aux attentes des lecteurs.

\section{AUTEURS}

RÉMY BOUCHARLAT

CNRS, Lyon

POUPAK RAFII NEJAD

CNRS, UMR7528 - Mondes iranien et indien, Paris 